\title{
Perfil de Docentes Humanistas, Fenomenológicos e Existenciais: Análise de Editais de Concursos
}

\author{
Gabriel Nery Matos ${ }^{1}$ \\ Paulo Coelho Castelo Branco ${ }^{2}$ \\ ${ }^{1}$ Universidade Federal da Bahia, BA, Brasil. \\ ${ }^{2}$ Universidade Federal do Ceará, CE, Brasil. \\ Tommy Akira Goto ${ }^{3}$ \\ ${ }^{3}$ Universidade Federal de Uberlândia, MG, Brasil.
}

\begin{abstract}
Resumo: Com base no argumento de que existe um mercado de trabalho acadêmico público que indica um perfil formativo para contratar profissionais para atuar no ensino superior, objetivase analisar quais conhecimentos circulam em editais de concurso para a área humanista, fenomenológica e existencial. Inicialmente, percebe-se que no Brasil é comum vincular as perspectivas humanistas, fenomenológicas e existenciais de Psicologia com as perspectivas fenomenológicas e existenciais da Filosofia. Em seguida, apresenta-se o plano de coleta e a análise dos dados conforme o método da análise de conteúdo. Foram compilados 24 editais, dos quais se extraíram 241 pontos de conhecimento cujas unidades de registro temáticas foram organizadas segundo seis eixos temáticos que remetem ao perfil formativo estudado. Este aponta para uma composição de conhecimentos relacionados: aos fundamentos históricos, epistemológicos e filosóficos; aos entendimentos teórico-conceituais; às práticas clínicas; às atuações no campo da saúde; à formação para a pesquisa e intervenção; e à reflexão acerca de fenômenos atuais. Conclui-se que esse perfil formativo é vasto, plural, complexo e difícil de ser atingido/dominado em sua totalidade, considerando as explicações, delimitações, articulações, aplicações e implicações das mencionadas perspectivas. Por fim, questiona-se o motivo disso e se lança outra possibilidade de pesquisa em instituições privadas.

Palavras-chave: Análise de Conteúdo, Fenomenologia, Formação do Psicólogo, Psicologia Humanista, Universidades.
\end{abstract}

\section{The Profile of Humanistic, Phenomenological and Existential Educators: An Analysis of Public Selection Notice.}

\begin{abstract}
Following the argument that there is a public academic paper market that indicates the profile of professionals to work in higher education, this text analyzes the content of the knowledge required in public tenders for the phenomenological and existential humanist area. Initially, it can be observed that in Brazil it is common for the humanist, phenomenological and existential perspectives of psychology and philosophy to be associated. The data collection and analysis followed the content analysis method. Twenty-four public notices were selected, of which 241 points of knowledge were extracted whose recording thematic units were organized according to six thematic axes that refer to the formative profile studied. The knowledge detected was related to: historical, epistemological and philosophical foundations; theoretical-conceptual understandings; clinical practices; activities in the health field; training for research and intervention; and the understanding of current phenomena. This formative profile is shown to be broad, plural, complex and difficult to be reached/mastered in full, considering the explanations, determinations, articulations, applications and implications of the aforementioned mentioned perspectives. Lastly, the reason for such is questioned and another possibility of research in private institutions is proposed.
\end{abstract}

Keywords: Colleges, Content Analysis, Humanistic Psychology, Phenomenology, Psychologist Education. 


\title{
Perfil de Docentes Humanistas, Fenomenológicos y Existenciales: Análisis de Convocatorias de Concursos
}

\begin{abstract}
Resumen: Con base en el argumento de que existe un mercado de trabajo académico público que indica un perfil formativo en la contratación de profesionales para actuar en la enseñanza superior, se pretende analizar qué conocimientos circulan en convocatorias de concurso público para el área humanista, fenomenológica y existencial. Inicialmente, se sitúa que en Brasil es común vincular las perspectivas humanistas, fenomenológicas y existenciales de psicología y con las perspectivas fenomenológicas y existenciales de filosofía. A continuación, se presenta el plan de recolección y el análisis de los datos según el método del análisis de contenido. Se han compilado 24 convocatorias, de las cuales se extrajeron 241 puntos de conocimiento cuyas unidades de registro temáticas fueron organizadas según seis ejes temáticos que remiten al perfil formativo estudiado. Este apunta a una composición de conocimientos relacionados a: los fundamentos históricos, epistemológicos y filosóficos; los entendimientos teóricoconceptuales; las prácticas clínicas; las actuaciones en el campo de la salud; la formación para la investigación e intervención; y la reflexión sobre fenómenos actuales. Se concluye que ese perfil formativo es vasto, plural, complejo y difícil de ser alcanzado/dominado en su totalidad, considerando las explicaciones, delimitaciones, articulaciones, aplicaciones e implicaciones de las mencionadas perspectivas. Se cuestiona el motivo de ello y se lanza otra posibilidad de investigación en instituciones privadas.
\end{abstract}

Palabras clave: Análisis de Contenido, Fenomenología, Formación del Psicólogo, Psicología Humanista, Universidades.

\section{Introdução}

A temática da formação do psicólogo tem se constituído como um campo profícuo de pesquisas e discussões em todas as regiões do Brasil (Amendola, 2014; Ferreira Neto, 2004; Yamamoto \& Costa, 2010), principalmente a partir das "novas" diretrizes curriculares da Psicologia publicadas em 2004. Existem, pois, mapeamentos de produções sobre o tema que indicam certa dispersão metodológica e conceitual no seu trato, abrangendo várias áreas da Psicologia (Costa et al., 2012).

Dentre as correntes psicológicas que se inserem nessas pesquisas situamos a denominada "psicologia humanista", circunscrita no vasto domínio das perspectivas científicas e profissionais de Psicologia e composta por variadas escolas que compartilham uma visão positiva dos potenciais humanos e dos seus aspectos inter-relacionais. Fundada oficialmente em 1961, a psicologia humanista é caracterizada como uma congregação de psicólogos que desenvolveram diversas perspectivas de intervenções individuais e grupais, além de elaborar um escopo de pesquisas empíricas (Castelo-Branco \& Silva, 2017;
Holanda, 2014). Alguns exemplos de expoentes dessa perspectiva são Abraham Maslow, Carl Rogers, Gordon Allport, Clark Moustakas, Rollo May, Fritz Perls, entre outros (Castañon, 2007).

Em distinção à psicologia humanista estadunidense, percebemos que no Brasil existe a filiação desta com algumas outras abordagens de influências filosóficas fenomenológicas e existenciais, entendidas também como humanistas - destacamos o psicodrama, a psicologia existencial, a logoterapia e até mesmo a daseinsanálise. Com efeito, no Brasil, os aportes da fenomenologia e do existencialismo parecem, frequentemente, ser o denominador comum que suscita a comunhão das distintas abordagens consideradas humanistas (Castelo-Branco, Matos, Sampaio \& Amaral, 2017; Feijoo \& Mattar, 2016; Amatuzzi, 2009; Holanda, 1997), congregando-as em um espaço de ensino e desenvolvimento daquele conhecimento psicológico que não está situado nos campos psicanalíticos, comportamentais e cognitivistas. No entanto, como destaca Goto (2015), por um lado a fenomenologia e, consequentemente, o existencialismo tiveram 
uma relação positiva com a Psicologia, possibilitando a criação e o desenvolvimento de "novas" abordagens/escolas dentro desse campo do conhecimento, tais como as psicologias humanista, fenomenológica e existencial; por outro, essa relação também proporcionou uma série de equívocos e confusões conceituais em torno dessa relação, ainda presentes entres os psicólogos brasileiros.

Após esse breve panorama, convém apontar a existência de alguns espaços de circulação de conhecimento que retratam o movimento da psicologia humanista brasileira. Entende-se que a noção de circulação (Grynzspan, 2012) implica neste estudo o entendimento de como as ideias humanistas nacionais estão sendo organizadas e propagadas de acordo com certas operações sociais-institucionais como, por exemplo, a publicação de editais de concurso público para contratar profissionais humanistas, fenomenológicos e existenciais, com a finalidade de compor o quadro docente de uma universidade e formar discentes dessa tradição psicológica.

Ressalta-se que, no Brasil, a formação científica/ profissional está amplamente relacionada às universidades, espaço privilegiado de formação de profissionais responsáveis por fazer e gerenciar a ciência e suas intervenções nos mais diversos campos de trabalho (Yamamoto \& Costa, 2010). Ainda, os cursos de graduação devem oferecer uma formação ampla e que tenha princípios o "reconhecimento da diversidade de perspectivas necessárias para compreensão do ser humano e [o] incentivo à interlocução com campos de conhecimento que permitam a apreensão da complexidade e multideterminação do fenômeno psicológico" (Conselho Nacional de Educação, 2004). Dessa forma, os cursos devem apresentar e informar os discentes sobre a diversidade das teorias, métodos e práticas da Psicologia, mesmo que de forma geral ainda estejam sintetizadas nas denominadas "forças" ou "abordagens".

Destarte, objetivamos analisar os conteúdos expostos em editais de concursos de Instituições de Ensino Superior (IES) públicas para contratar psicólogos com o perfil humanista, fenomenológico e/ou existencial. Tal proposta ocorre mediante $\mathrm{o}$ argumento de que existe hoje no Brasil um mercado de trabalho profissional e acadêmico que estabelece critérios formativos específicos para contratar psicólogos desse perfil, com o intuito de formar discentes nessas perspectivas. Com efeito, parte-se da seguinte pergunta: qual é o perfil formativo de conhecimento esperado de um psicólogo humanista, fenomenológico e existencial para ser docente em cursos de Psicologia de IES públicas?

\section{Método}

Para responder à questão apresentada, escolheu-se como método a análise de conteúdo inspirada pelos princípios de Bauer (2000/2002), de modo que seja possível analisar os editais selecionados através de seus pontos de conhecimento, os quais expressam os assuntos que os candidatos devem conhecer e pelos quais serão avaliados durante o certame seletivo, sobretudo nas provas escrita e didática. Salienta-se que a escolha de editais de concursos públicos ocorreu pela necessidade de acessar alguma base de dados que organize as informações legais e publicizadas que são intencionadas pela pesquisa. Dessa maneira, o fato das instituições privadas nem sempre publicizarem oficialmente seus editais de seleção tornou a pesquisa com instituições públicas um caminho mais viável ao processo de pesquisa, pois, diferente das IES privadas, as públicas têm bancos de registros públicos e duradouros que permitem o acesso por via aberta e gratuita aos seus documentos, a exemplo do Diário Oficial da União (DOU). Também se pode somar ao argumento, conforme constatou Orengo (2017), que as IES públicas têm oferecido mais disciplinas de psicologia humanista, fenomenológica e existencial que as instituições particulares.

Como via de acesso a essa esfera informativa houve o entendimento dos editais como documentos viáveis por nutrir as seguintes características: são textos registrados em papel, acessados pela via digital e que funcionam como documento impresso; e pode-se acessar sua natureza enquanto documento legal e formal público, por funcionarem como mensagens enviadas à sociedade civil por entidades públicas (IES). Em suma, a publicação de editais em um diário oficial serve como elemento de demarcação da via pública, o que gera documentos passiveis de pesquisa (Cellard, 1997/2008).

Com efeito, o critério de inclusão dos editais para a coleta de dados foi que estes fossem publicados por uma universidade federal ou estadual e possuíssem em sua área qualquer conhecimento e perfil relacionados às psicologias humanista, fenomenológica e existencial, independente da classe (auxiliar, assistente ou adjunto) e do regime de trabalho (20 horas, 40 horas, 
dedicação exclusiva). Para além de uma pesquisa virtual no DOU, foram consultados, também, sites de universidades públicas e o site "PCI Concursos", específico à busca de concursos e editais. Além disso, foram enviados e-mails para professores que trabalham em uma perspectiva humanista, fenomenológica e/ou existencial, solicitando que estes colaborassem com a pesquisa cedendo, quando possível, os editais dos concursos a que eles se submeteram. Essa captação ocorreu de novembro de 2016 até julho de 2017.

Durante o processo de coleta dos editais, no que concerne às divisões regionais nacionais, somente na região Sul não foi possível encontrar editais. Na tentativa de explicar tal ausência, inferimos, a partir de conversas com alguns professores de IES sediadas no Sul, que os editais que os captaram não visavam abordagens humanistas, fenomenológicas e existenciais, e sim serviços ou áreas de atuação mais gerais (como psicologia clínica, por exemplo). Assim, por coerência ao que foi estabelecido metodologicamente, não se computou os editais pelos quais eles foram contratados. Com efeito, foram compilados 24 editais: cinco na região Sudeste, sete na região Centro-Oeste, nove na região Nordeste e três na região Norte. Durante o período da coleta, ocorreram repetições de editais nas fontes de busca utilizadas, sugerindo uma possível saturação do material (dadas as vias de acesso escolhidas). Apesar de julgar essa amostra como representativa para as intenções da pesquisa, por certo, existiram editais que não conseguimos coletar.

A demarcação temporal dos editais coletados abrangeu desde o ano de 2008, ano do edital mais antigo compilado, até 2016, ano do último edital lançado durante o período da coleta. Com base no material adquirido, organizamos 241 pontos para leitura posterior, seguindo o método supracitado. Esses pontos foram armazenados em tabelas. Posteriormente, seguindo as etapas do método (Bauer, 2000/2002), houve uma leitura geral desses com o intento de se ter um primeiro contato com as informações relevantes ao ingresso do psicólogo humanista, fenomenológico e existencial nas IES. Em um momento seguinte, procedemos de outra leitura que mapeou as unidades de registro temáticas relacionadas aos temas dispostos nos pontos de cada edital compilado. Os eixos pensados à luz desses pontos foram os seguintes: Fundamentos Históricos, Epistemológicos e Filosóficos; Perspectivas Teórico-Conceituais; Perspectivas Clínicas; Perspectivas relacionadas ao campo da Saúde; Formação e Pesquisa; e Tópicos Atuais. Isso permitiu a codificação e a identificação das frequências de aparições dessas unidades. Esta etapa possibilitou, por fim, algumas inferências a partir do estabelecimento de eixos temáticos que levaram à compreensão de um perfil formativo de conhecimento para a contratação desse público docente.

\section{Resultados e discussão}

Neste tópico será apresentada a discussão dos eixos temáticos encontrados, de modo que fique claro o conteúdo inferencial constituído pelas unidades temáticas tabuladas. Inicialmente, estas remeteram a um conhecimento sobre os "Fundamentos Históricos, Epistemológicos e Filosóficos” das perspectivas humanistas, fenomenológicas e existenciais da Psicologia, conforme expresso a seguir na Tabela 1.

\section{Tabela 1}

Eixo 1: Fundamentos Históricos, Epistemológicos e Filosóficos.

\begin{tabular}{lcc}
\hline \multicolumn{1}{c}{ Unidades Temáticas (Conteúdos) } & F & \% \\
\hline $\begin{array}{l}\text { Perspectivas epistemológicas da } \\
\text { psicologia humanista }\end{array}$ & 12 & 27,27 \\
$\begin{array}{l}\text { Fundamentos da fenomenologia } \\
\text { Perspectivas filosóficas da psicologia }\end{array}$ & 10 & 22,73 \\
$\begin{array}{l}\text { humanista } \\
\begin{array}{l}\text { Perspectivas históricas da psicologia } \\
\text { humanista }\end{array}\end{array}$ & 8 & 20,45 \\
$\begin{array}{l}\text { Idealismo, empirismo e } \\
\text { fenomenologia }\end{array}$ & 3 & 6,82 \\
$\begin{array}{l}\text { As dimensões do fenômeno e da } \\
\text { consciência intencional }\end{array}$ & 2 & 4,55 \\
Total & 44 & 100 \\
\hline
\end{tabular}

Considerando os pontos que foram utilizados na construção deste eixo temático, é possível perceber a existência de conteúdos que buscam contemplar um perfil profissional condizente com os entendimentos sobre as fundamentações do campo. Abre-se, pois, a possibilidade de algumas inferências sobre isso.

A primeira implica uma tendência nacional pela pesquisa/formação direcionada aos fundamentos históricos, epistemológicos e filosóficos, em uma tentativa de entendimento e demarcação do que é diretamente ligado à fundação dos pensamentos humanistas, fenomenológicos e existenciais nos campos da Psicologia e da Filosofia, assim como às influências que a fenomenologia e o existencialismo 
exerceram na psicologia humanista, em suas diversas abordagens (Holanda, 2014). Dessa maneira, a busca pela organização e demarcação epistêmica denota um trabalho de organização, encadeamento e delimitação dos conhecimentos que possibilitaram a constituição do campo psicológico humanista nos anos de 1950-1970, perante a American Psychological Association (Castañon, 2007).

Credita-se a Abraham Maslow a congregação de pessoas e a compilação de ideias divergentes do conhecimento psicológico hegemônico daquela época - de norte cultural psicanalítico e behaviorista. A Maslow, também, pode ser atribuída a iniciativa de postular condições estruturantes para a prática dos profissionais integrantes da perspectiva humanista, fenomenológica e existencial (Castelo-Branco \& Silva, 2017). Nesse sentido, outros humanistas, como Rollo May, Carl Rogers e Amedeo Giorgi, se preocuparam em tecer relações com os aportes fenomenológicos e existenciais, trazendo implicações para a pesquisa empírica e a psicoterapia, ao passo que essa tendência de fundamentação permanece, ainda hoje, em diversas produções brasileiras (Boris, Melo \& Moreira, 2017; Castelo-Branco \& Cirino, 2016; Feijoo \& Mattar, 2014, 2016; Ponte \& Sousa, 2011; Gomes \& Castro, 2010).

O imperativo de conhecimento sobre as fundamentações históricas, epistemológicas e filosóficas da psicologia humanista, fenomenológica e existencial, em uma perspectiva brasileira, expressa uma tentativa de reposicionamento histórico ante a recepção dessa vertente que foi dividida em dois momentos constitutivos da psicologia humanista nacional (Gomes, Holanda \& Gauer, 2004; Prestelo, 2012). O primeiro seria um momento vivencial (1970-1980), caracterizado pelas vindas de expoentes humanistas que demonstraram a sua prática a partir de workshops e atividades grupais. Nesse momento, a psicologia humanista circulou, predominantemente, em um cenário extra-acadêmico, em que o exercício e o aprendizado direto da prática experiencial sobrepujavam erudições e explicações teóricas sobre esse fazer profissional.

A partir de alguns movimentos críticos a essa falta de teorização emergiu outro momento da recepção da psicologia humanista no Brasil, em que se reivindicou uma retomada das fundações e assunção dos fundamentos humanistas, fenomenológicos e existenciais da Psicologia, perdurando de 1990 até os dias de hoje (Goto, 2015). Mesmo assim, os dados colhidos apresentam um cenário ainda amplo, confuso e diverso.
Esse cenário pode ser confirmado, como mostra a pesquisa realizada por Orengo (2017), a partir da compreensão de psicólogos brasileiros sobre os termos utilizados nas disciplinas universitárias ligadas à Psicologia fenomenológica, em que foram encontrados 95 nomes variados. Destes, 50 nomes possuíam o termo fenomenologia ou fenomenológica(o); 35 eram associados ao termo existencial ou existencialismo; 14 continham o termo humanista ou humanismo; e, por fim, 4 nomes de disciplinas apresentavam o termo Gestalt ou Gestalt-terapia.

A partir desse último momento direcionado à busca por fundamentos, surgem delimitações que visam explicar as fronteiras e entrelaçamentos da fenomenologia e do existencialismo com as práticas psicológicas na clínica, no método de pesquisa e na constituição de uma visão de homem e mundo (Castañon, 2007; Castelo-Branco \& Cirino, 2016; Feijoo \& Mattar, 2017; Holanda, 1997, 2014). Contudo, aponta-se um conflito epistêmico que rodeia a designação "psicólogo humanista-fenomenológico-existencial", pois há uma tendência de situar nela lugares de pensamento que, por estarem afastados das correntes comportamentais, psicanalíticas e cognitivistas, são atrelados genericamente ao "olhar" humanista. Do mesmo modo, denominações como "humanista existencial ou fenomenológico existencial" expõem uma tentativa de abranger áreas que podem ter pontos de proximidade, mas com lugares epistêmicos bastante ou sutilmente diferentes (Goto, 2015; Holanda, 2014).

Com efeito, por mais que se percebam as questões concernentes ao complexo processo de organização do lugar humanista atual, há uma junção estabelecida com os saberes fenomenológicos e existenciais que torna difícil, senão problemático, alguma separação ou aproximação. Um reflexo disso são os editais que buscam um perfil docente orientado ao entendimento dos mencionados fundamentos, o que demonstra $o$ quão diversificado pode ser esse caminho de acesso às raízes humanistas. Nesse sentido, este eixo requer um entendimento da vida e obra (linhas de pensamento) dos mencionados expoentes humanistas e de alguns filósofos de orientação fenomenológica, como Edmund Husserl e Martin Heidegger, por exemplo. Além disso, as perspectivas epistemológicas e filosóficas da psicologia humanista também requerem conhecimentos relacionados à filosofia existencial, o que gera incursões aos pensamentos de Søren Kierkegaard e de Martin Buber, por exemplo. 
É interessante destacar que, ao mesmo tempo em que se exige a fundamentação histórica e epistemológica da filosofia fenomenológica e do existencialismo, os psicólogos formados nessa tradição, conforme evidencia Orengo (2017), apresentam ainda "um desconhecimento quanto aos fundamentos básicos da fenomenologia iniciada por Husserl", sendo "notória a falta de compreensão dos psicólogos 'fenomenólogos' quanto à vocação da fenomenologia como fundamento filosófico basal para a constituição das ciências, em especial a Psicologia" (p. 33).

Com essa diversidade e complexidade de pensamentos, percebemos e organizamos outro eixo temático vinculado às fundamentações teórico-conceituais que adentram um plano de consistência explicativa das linhagens humanistas. Pode-se explorar essa diversidade nesse segundo eixo, intitulado "Perspectivas Teórico-Conceituais" e expresso em seguida na Tabela 2.

Tabela 2

Eixo 2: Perspectivas Teórico-Conceituais.

\begin{tabular}{lcc}
\hline \multicolumn{1}{c}{ Unidades Temáticas (Conteúdos) } & F & $\mathbf{\%}$ \\
\hline Conceitos da Gestalt-terapia & 11 & 14,67 \\
Personalidade & 11 & 14,67 \\
Teorias da psicologia humanista & 10 & 13,33 \\
Conceitos da abordagem centrada & 10 & 13,33 \\
na pessoa & 8 & 10,67 \\
Conceitos do psicodrama & & \\
Comparações: aproximações e & 7 & 9,33 \\
distanciamentos entre as abordagens & & 5,33 \\
Relação interpessoal & 4 & 5,33 \\
Corpo & 4 & 4,00 \\
Cuidado & 3 & 4,00 \\
Limites e possibilidades teóricas & 3 & 2 \\
Subjetividade & 1 & 1,67 \\
Fenomenologia transcendental & 1 & 1,33 \\
Identidade & 75 & 100 \\
Total & & \\
\hline
\end{tabular}

Partindo dessa tabela, é possível observar temas de estirpe teórica e conceitual, como "Teorias da psicologia humanista", "Conceitos da Gestalt-terapia", "Conceitos da abordagem centrada na pessoa" e "Personalidade", que alcançaram dois dígitos em suas incidências. Essas unidades temáticas apontam, por exemplo, para explicações conceituais sobre o que é self, tendência à realização, contato, empatia, experiência, etc. Portanto, pode-se considerar que o conhecimento sobre os aspectos teóricos e conceituais da área humanista são esperados como um imperativo de conhecimento desejado pelas IES pesquisadas. A partir desse resultado, propõem-se algumas reflexões.

O eixo temático 2 remete a um sentido de aplicação que possibilita uma ponte entre as abstrações teóricas e as intervenções relacionais que compõem as correntes humanistas, fenomenológicas e existenciais, como também às aproximações e distanciamentos que identificam possíveis inter-relações entre elas. Cabe acrescentar que em outra pesquisa, a qual organizou uma revisão sistemática sobre as produções relacionadas à formação do psicólogo humanista no Brasil (Castelo-Branco et al., 2017), encontraram-se alguns resultados que coadunam com este perfil tematizado, no quesito de haver uma tendência para enfatizar discussões teórico-conceituais que fundamentem a formação humanista, fenomenológica e existencial. Em consonância com a revisão retrocitada, aponta-se para a necessidade de um equilíbrio entre a teoria e a valorização existencial e relacional do processo terapêutico - dilema já apontado por outros expoentes humanistas (Perls, 1973/1988; Rogers, 1961/2009). Consequentemente, existe um perfil que busca uma articulação dos elementos teóricos com os aspectos elucidados no eixo anterior ("Fundamentos Históricos, Epistemológicos e Filosóficos”) e as implicações para as práticas vivenciais e relacionais.

A partir das unidades temáticas levantadas, observam-se focos em diferentes correntes teóricas. Esse aspecto foi considerado para possíveis mapeamentos do perfil estudado, conforme se solicita incursões em variadas teorias psicológicas humanistas, fenomenológicas e existenciais, das quais predominam a abordagem centrada na pessoa e a Gestalt-terapia. Contudo, é necessário ter, ainda, um conhecimento sobre outras abordagens como o psicodrama, a logoterapia e a daseinsanálise, por exemplo. Observando de modo panorâmico as unidades temáticas expostas na Tabela 2, as informações ali contidas abrem, também, possibilidades para pensar interfaces dessas teorias com as noções de corpo, cuidado e personalidade.

O terceiro eixo temático, nomeado como "Perspectivas Clínicas", indicado a seguir na Tabela 3, revela o quanto o conhecimento humanista está atrelado ao campo clínico, dado que as principais correntes teóricas (abordagens) mencionadas foram pensadas a partir dessa atuação, que se mostra como algo complementar ao perfil formativo estudado. 
Tabela 3

Eixo 3: Perspectivas Clínicas.

\begin{tabular}{lcc}
\hline Unidades Temáticas (Conteúdos) & F & \% \\
\hline Psicoterapia na perspectiva & 15 & 22,73 \\
fenomenológica existencial & 9 & 13,64 \\
Intervenções grupais & 8 & 12,12 \\
Metodologia clínica & 5 & 7,58 \\
Psicodiagnóstico & 5 & 7,58 \\
Psicologia clínica & 4 & 6,06 \\
Ética na clínica & 4 & 6,06 \\
Ludoterapia infantil & 2 & 3,03 \\
Psicoterapia individual & 2 & 3,03 \\
Aconselhamento psicológico & 2 & 3,03 \\
Avaliação psicológica & 2 & 3,03 \\
Escuta clínica & 2 & 3,03 \\
Ludoterapia clínica & 2 & 3,03 \\
Ludoterapia grupal & 2 & 3,03 \\
Processo terapêutico & 1 & 1,51 \\
Entrevista clínica & 1 & 1,51 \\
Visão de cliente & 66 & 100 \\
Total & &
\end{tabular}

Conforme a Tabela 3 demonstra, há um valor significativo em unidades temáticas como "Metodologia clínica", "Intervenções grupais" e "Psicoterapia na perspectiva fenomenológica existencial", pontos que dialogam com os eixos anteriores no que remete às discussões das construções conceituais como ferramentas na ação clínica. O conteúdo "Psicoterapia na perspectiva fenomenológica existencial”, por exemplo, funciona como uma unidade temática que praticamente requer uma interface com os conhecimentos históricos, dissertados no primeiro eixo, e com os desenvolvidos no segundo - pois aponta para uma reflexão sobre os entrelaçamentos filosóficos e psicológicos na prática clínica, de um ponto de vista histórico, epistêmico, teórico e prático.

Dentre as áreas de atuação do psicólogo, a clínica costuma ser o ramo mais atrelado à prática profissional (Ferreira Neto, 2004), com a formação de seu campo feito por teóricos que construíram suas perspectivas na prática da psicoterapia humanista, fenomenológica e existencial (Holanda, 1997). Destarte, não é grande surpresa que no processo avaliativo para ingressar em uma IES a busca pelo perfil clínico esteja presente e interligado às erudições teóricas e práticas.
Corroborando com este dado, considera-se, novamente, a revisão sistemática feita por CasteloBranco et al. (2017), que dentre as categorias construídas, com enfoque no campo formativo do psicólogo humanista no Brasil, demonstrou em seus resultados uma preponderância de artigos que observavam o espaço formativo pela via clínica. A psicoterapia, como um serviço clínico, colhe frutos diretos das questões veiculadas a discussões e construções teóricas, bem como das implicações referentes às buscas por fundamentações epistêmicas, históricas e filosóficas. Em decorrência disso, esse perfil busca integrar os saberes humanistas aos fenomenológicos e existenciais e/ou problematizar essa relação, no sentido de pensar a prática psicoterapêutica, seja na abordagem centrada na pessoa (Castelo-Branco \& Cirino, 2016), na Gestalt-terapia (Boris et al., 2017) ou em um desenvolvimento humanista, fenomenológico e existencial mais geral (Amatuzzi, 2009; Feijoo \& Protasio, 2015; Gomes \& Castro, 2010).

Em síntese, percebe-se a necessidade de entendimento da psicologia humanista em suas interfaces com a clínica, nos âmbitos individuais, grupais e infantis, ou em questões mais gerais, como a ética na clínica, a questão do psicodiagnóstico etc., fazendo parte desse entendimento leituras da visão de mundo e de ser humano das filosofias existenciais e fenomenológicas na prática clínica - saberes que devem ser considerados no perfil estudado.

O quarto eixo temático, alcunhado de "Perspectivas relacionadas ao campo da saúde", expresso em seguida na Tabela 4, versa, de modo semelhante ao eixo anteriormente discutido, as interfaces dos saberes humanistas, fenomenológicos e existenciais com esse campo.

Tabela 4

Eixo 4: Perspectivas relacionadas ao campo da Saúde.

\begin{tabular}{|c|c|c|}
\hline Unidades Temáticas (Conteúdos) & $\mathbf{F}$ & $\%$ \\
\hline $\begin{array}{l}\text { Saúde-doença do ponto de vista } \\
\text { fenomenológico-existencial }\end{array}$ & 7 & 14,58 \\
\hline Psicopatologia fenomenológica & 6 & 12,50 \\
\hline Clínica ampliada & 5 & 10,42 \\
\hline Saúde mental & 5 & 10,42 \\
\hline Plantão psicológico & 4 & 8,33 \\
\hline $\begin{array}{l}\text { A atenção em psicologia da saúde } \\
\text { sob o enfoque fenomenológico- } \\
\text { existencial. }\end{array}$ & 4 & 8,33 \\
\hline
\end{tabular}

continua... 


\begin{tabular}{lcc}
...continuação & & \\
\hline Unidades Temáticas (Conteúdos) & F & \% \\
\hline Políticas públicas & 3 & 6,25 \\
Atenção psicológica & 3 & 6,25 \\
Normal e patológico & 2 & 4,17 \\
SUS & 2 & 4,17 \\
Políticas públicas de saúde no & 2 & 4,17 \\
Brasil & 2 & 4,17 \\
Psicodrama e saúde & 2 & 4,17 \\
Humanização em saúde & 1 & 2,07 \\
Redes substitutivas de atenção à & & 100 \\
saúde mental & 48 & \\
Total & & \\
\hline
\end{tabular}

Este eixo temático apresenta em suas porcentagens um equilíbrio maior entre as unidades captadas, tendo sua pertinência indicada pela constância de temas que caracterizam discussões sobre o campo da saúde nos editais pesquisados. Percebe-se, ainda, que em seus assuntos há uma transição entre questões direcionadas à saúde mental e outras às políticas públicas e seus dispositivos.

A saúde mental pode ser entendida pelos temas mais tradicionais da Psicologia como a questão do psicodiagnóstico e da concepção de normal e patológico, segundo os pensamentos humanistas, fenomenológicos e existenciais, os quais apresentam um posicionamento crítico à estrutura tradicional de saúde (Castañon, 2007), restrita ao diagnóstico de uma doença e à catalogação de sintomas com o tratamento voltado para a eliminação deles (Faizibaioff \& Antúnez, 2015). Contudo, no eixo 4 se leva em consideração os temas relacionados à reforma psiquiátrica, conhecimento que pede um posicionamento do profissional humanista, fenomenológico e existencial. A partir desse raciocínio, nota-se a presença de discussões sobre as políticas públicas e práticas de humanização, entendendo-as como questões efervescentes nos últimos anos do cenário profissional (Ferreira Neto, 2017). Os dados mostram o interesse por conhecimentos que promovam a prática humanista, fenomenológica e existencial nos serviços e espaços condizentes a essas políticas. Destaca-se uma pertinência na referência à Clínica ampliada e ao Plantão psicológico, indicando-os como importantes meios de atuação profissional para lidar com os desafios que esse cenário tem apresentado. Este dado também esteve presente nos estudos de Amorim, Andrade e Castelo-Branco (2015), Scorsolini-Comin (2015) e Castelo-Branco et al. (2017).
Cabe ainda uma relação do eixo 4 ("Perspectivas relacionadas ao campo da Saúde”) com o eixo 3 (“Perspectivas Clínicas"), pois mesmo que estas tenham se configurado como um conhecimento importante dentre os serviços que marcam a atuação humanista, fenomenológica e existencial, o cenário político nacional e as respectivas consequências de trabalhos e propostas em relação às resolutivas governamentais implicam uma revisão e empreendimento de novos modelos de atuação que considerem as esferas públicas de saúde. Dessa forma, um contexto político externo ao campo humanista, fenomenológico e existencial influencia diretamente a prática do mesmo. Essa nova realidade sai da lógica formativa psicológica tradicional que tinha, hegemonicamente, produções intelectuais e formações profissionais baseadas nas áreas clínica, organizacional e educacional (Ferreira Neto, 2004). Assim, o eixo 4 tem em seus temas colhidos pontos que se aproximam das questões mais teóricas e fundamentais do campo humanista, fenomenológico e existencial, como também aspectos direcionados à prática $\mathrm{e}$ ao desenvolvimento de novas perspectivas de atuação. Logo, define-se isso como um conhecimento necessário para a contratação do profissional no perfil estudado.

O quinto eixo, nomeado de "Formação e Pesquisa", evoca os aspectos formativos para atuar na esfera da pesquisa, conforme se expõe a seguir na Tabela 5 .

Tabela 5

Eixo 5: Formação e Pesquisa.

\begin{tabular}{lcc}
\hline Unidades Temáticas (Conteúdos) & F & $\mathbf{\%}$ \\
\hline Metodologia de pesquisa & 6 & 23,08 \\
Formação do psicólogo & 4 & 15,38 \\
Campos de atuação profissional & 4 & 15,38 \\
Limites e possibilidades de atuação & 3 & 11,54 \\
Supervisão & 2 & 7,69 \\
Ética em pesquisa & 2 & 7,69 \\
Ética na perspectiva & 2 & 7,69 \\
fenomenológica-existencial & 2 & 7,69 \\
Pesquisa fenomenológica & 1 & 3,86 \\
Visão de ciência & 26 & 100 \\
Total & & \\
\hline
\end{tabular}

A "Formação e Pesquisa" aparece como um eixo que corresponde às discussões anteriores, pois está atrelada à busca por fundamentações, ao rigor teórico e aos campos de atuação profissional. Além disso, 
relaciona-se ao embasamento prático que ampara essa ação. Dessa maneira, o campo formativo para a pesquisa figura como um elemento importante à construção de uma identidade profissional humanista, fenomenológica e existencial. A unidade temática "Metodologia de pesquisa" demonstra a maior frequência no eixo 5 pela configuração de pesquisas nessa perspectiva.

Segundo Amatuzzi (2009), é pauta de reflexão e problematização da psicologia humanista a adequação dos seus objetos de estudo (geralmente entendidos como experiências de algo) ao paradigma positivista vigente na ciência moderna. Por uma senda, existe uma tentativa em adequar os objetos de estudo ao uso de métodos tradicionais de pesquisa; por outra mirada, há uma busca de construção metodológica que valide e ratifique outro lugar de produção de conhecimento legítimo ao campo humanista, mantendo os mesmos objetos. Neste outro lugar, aponta-se um modelo de pesquisa influenciado pelas correntes fenomenológicas (empírica e experimental) e existenciais (fenomenológico-hermenêuticas). Consoante o mencionado autor,

Tomando uma direção um pouco diferente, em alguns lugares fala-se de uma psicologia fenomenológica como um saber que se constrói e se exerce não a partir do interior da filosofia (se bem que sempre inspirado nela), mas, agora, a partir do interior da própria psicologia enquanto um fazer científico. . . Com ênfases diferentes, alguns autores pretenderam construir uma psicologia de inspiração fenomenológica husserliana (mais do que heideggeriana) e que pudesse ser considerada um fazer científico, embora trabalhasse em uma direção descritiva qualitativa e não quantitativa.... É nesse sentido que se pratica uma psicologia fenomenológica no contexto da psicologia humanista: elucidação do vivido baseada na consideração de experiências concretas e situadas, conduzindo a uma compreensão teórica que possibilite lidar melhor com o fenômeno (Amatuzzi, 2009, p. 96).

Em complemento à pesquisa, a formação tem sido um objeto de estudo recorrente na atualidade (Ferreira Neto, 2004). No entanto, unidades temáticas como "Formação do psicólogo", "Campos de atuação profissional” e "Limites e possibilidades de atuação", além de exercerem aproximação com a discussão da pesquisa, demonstram interface com questões gerais da atuação prática, ou seja, uma preocupação da formação de pesquisa para dar conta de compreender, avaliar e intervir em problemas relacionados ao campo profissional.

O entendimento desse eixo temático pode caminhar, também, através de inferências que condizem às unidades temáticas "Supervisão", "Ética em pesquisa” e "Ética na perspectiva fenomenológica-existencial". Assim, é possível pensar como o aludido paradigma humanista, fenomenológico e existencial implica atuações diferenciadas no processo formativo, sendo a supervisão talvez um ponto que demarque a necessidade de uma ética na relação horizontal entre supervisor-estagiário e profissional-cliente (Castelo-Branco et al., 2017). O perfil docente perfilhado, a partir do que foi expresso, deve possuir um conhecimento relacionado à pesquisa e à formação, que se justifica na concepção da universidade segundo as dimensões do ensino, da pesquisa e da extensão.

O sexto e último eixo levantado, intitulado “Tópicos Atuais”, demarca uma tendência para refletir questões contemporâneas que solicitam um posicionamento do profissional psicólogo. Neste eixo, obtiveram-se as seguintes unidades temáticas (conteúdos): “Questões contemporâneas" (F = 7; 46,66\%); "Clínica contemporânea" ( $\mathrm{F}=4 ; 26,67 \%$ ); "Atualidades das abordagens humanistas, fenomenológicas e existenciais" $(\mathrm{F}=4 ; 26,67 \%)$. Dentre os eixos pensados à luz do material coletado, os "Tópicos Atuais" expressam, de certo modo, o que se espera das explorações pensadas no eixo anterior ("Formação e pesquisa"), pois o caminho para acessar novos entendimentos ocorre no âmbito da pesquisa. A unidade temática "Questões contemporâneas”, em específico, abre um leque de possibilidades para pensar inserções e aplicações a diversos assuntos que originariamente não figuram como discussões humanistas, fenomenológicas e existenciais, como relacionamentos virtuais, desenvolvimento computacional, influência de smartphones e questões ligadas à transgeneridade, por exemplo.

Com as unidades temáticas "Clínica contemporânea" e "Atualidades das abordagens humanistas, fenomenológicas e existenciais", abre-se espaço para se pensar questões atuais no cenário tradicional da clínica, como a psicoterapia virtual ou até mesmo intervenções voltadas para as novas configurações familiares. O perfil exigido para a contratação docente 
estudada, destarte, parece cada vez mais integrado a uma produção de conhecimento sobre alguns fenômenos recentes que implicam novos entendimentos.

\section{Considerações finais}

Este estudo teve como objetivo refletir sobre o perfil formativo de conhecimento que IES requerem ao psicólogo humanista, fenomenológico e existencial que visa atuar na esfera acadêmica pública, a partir da análise de conteúdo de editais de concurso. Em vista desse objetivo e dos dados encontrados, pôde-se pensar seis eixos que aparecem como pontos de conhecimento presentes no perfil formativo exigido por esse mercado, a saber: Fundamentos Históricos, Epistemológicos e Filosóficos; Perspectivas TeóricoConceituais; Perspectivas Clínicas; Perspectivas relacionadas ao campo da Saúde; Formação e Pesquisa; e Tópicos Atuais.

Com o transcurso das inferências apresentadas, conclui-se que existe uma lógica de conhecimento que busca por novidades, através de discussões, aproximações teóricas com temas atuais e da exploração de novos campos de implementação prática. Apesar disso, ainda é bastante presente a perspectiva clínica que norteia a construção teórica das principais correntes humanistas, fenomenológicas e existenciais, além de abranger suas estruturações e delimitações nos âmbitos histórico, epistemológico, filosófico, teórico e prático. Destacam-se as solicitações para desenvolver pesquisas e possíveis maneiras de ampliação do olhar científico segundo as correntes mencionadas.

Observamos, portanto, uma amplitude de conhecimento filosófico e psicológico exigido ao profissional humanista, fenomenológico e existencial que intencione ingressar em uma universidade pública. Existem, pois, atribuições de conhecimentos que são gerais à Psicologia, como os de pesquisa, atuação em áreas tradicionais (como a clínica) e políticas públicas. Há, ainda, a exigência por domínios teóricos, conceituais, epistêmicos e históricos que dificultam uma construção homogênea, clara e concisa dos conhecimentos, fazendo com que, em nosso juízo, beire a ordem da impossibilidade dominar profundamente tantos conhecimentos distintos e variados.

Ainda, alguns estudos têm mostrado o quanto existe de confuso e contraditório no entendimento desses domínios e na apropriação dos respectivos conceitos (Goto, 2015), além do notório desconhecimento das questões fundamentais da fenomenologia de Husserl (Orengo, 2017), por exemplo - prejudicando assim a propriedade das seleções. Editais de concurso em áreas como a psicanálise e o behaviorismo, segundo pudemos suscintamente observar em outros documentos os quais fugiram ao escopo desta pesquisa, demonstram a aquisição de um perfil mais homogêneo, claro e conciso. No campo humanista, fenomenológico e existencial isso não ocorre, pois é exigido ao candidato ter conhecimentos sobre: as abordagens humanistas, fenomenológicas e existenciais; as filosofias fenomenológicas e existenciais, seus expoentes e linhagens teóricas; suas aplicações e implicações para a pesquisa (métodos); a prática e a formação de psicólogos para atuar na clínica e em dispositivos de saúde; bem como os fenômenos atuais com os quais a Psicologia tem de lidar. Muitos desses conhecimentos, segundo ajuizamos, ainda requerem mais esclarecimentos sobre as suas relações, ao passo que, como afirmou nitidamente Krüger (2014), ainda é "desconhecida toda essa rede de relações conceituais e teóricas, sendo, portanto, desejável a realização de estudos bem detalhados" (p. 174).

Com efeito, segundo apreendemos, esse seria o perfil formativo geral que circula em editais de concurso que dizem respeito à contratação de um psicólogo humanista, fenomenológico e existencial para atuar em IES pública. Tal perfil, segundo ajuizamos, é vasto, plural, complexo e direciona-se ao confuso e provisório, tanto no que concerne ao conhecimento das filosofias fenomenológicas e existenciais quanto das escolas psicológicas humanistas, fenomenológicas e existenciais. Além disso, parece ser um perfil difícil de ser atingido/dominado em sua plenitude, considerando as explicações, delimitações, articulações, aplicações e implicações que perpassam esses referenciais de conhecimento.

A despeito deste estudo se deter a descrições desse perfil, que circula nos editais estudados, resta-nos indagar: por que não realizar mais concursos com um perfil exclusivo, bem delimitado a uma abordagem humanista, fenomenológica ou existencial? Será que isso não tornaria mais específico e dinâmico o processo de aquisição de um tipo de docente? A existência e a propagação desses docentes em IES públicas dependem desse perfil plural? Embora esses questionamentos sejam lançados para futuras reflexões, entendemos que isso não limita a possibilidade de profissionais humanistas, fenomenológicos e existenciais tentarem concursos e seleções em áreas de conhecimento mais 
gerais, inserindo esse saber dentro das instituições contratantes. Além disso, existe outro cenário formativo extra-acadêmico que contrata profissionais desse ramo e faz circular o conhecimento humanístico, fenomenológico e existencial.

Como limitação desta pesquisa aponta-se o delineamento direcionado para um perfil específico ao mercado profissional acadêmico público. Acrescenta-se a isso a falta de outras pesquisas do mesmo caráter para que se possa basear e comparar dados. Considerando que, no Brasil, o setor privado de IES concentra a maior parte dos cursos e docentes de Psicologia (Macedo, Lima, Dantas, \& Dimenstein, 2017), indica-se a possibilidade de novos estudos com enfoque em editais de universidades e faculdades privadas, possibilitando um maior mapeamento do perfil formativo estudado.

Para finalizar, um ponto de destaque e que merece um estudo histórico ulterior reside no fato que a filosofia fenomenológica parece ter penetrado na psicologia humanista brasileira, nos anos de 1980, mais pela necessidade de pesquisa e de rigor metodológico do que por questões prático-profissionais. Isso se dá uma vez que seus precursores, tais como, por exemplo, William B. Gomes (1985), Yolanda C. Forghieri (1984, 1989) e Mauro M. Amatuzzi (1989), reconhecidos psicólogos humanistas, estavam mais dedicados à pesquisa e à academia na busca de fundamentar uma base mais rigorosa para as práticas humanistas que se consolidavam no Brasil.

\section{Referências}

Amatuzzi, M. (1989). O significado da psicologia humanista: posicionamentos filosóficos implícitos. Arquivos Brasileiros de Psicologia, 41(4), 88-95.

Amatuzzi, M. (2009). Psicologia fenomenológica: uma aproximação teórica humanística. Estudos de Psicologia, 26(1), 93-100. http://dx.doi.org/10.1590/S0103-166X2009000100010

Amendola, M. (2014). Formação em psicologia, demandas sociais contemporâneas e éticas: uma perspectiva. Psicologia: Ciência e Profissão, 34(4), 971-983. http://dx.doi.org/10.1590/1982-370001762013

Amorim, F., Andrade, A., \& Castelo-Branco, P. (2015). Plantão psicológico como estratégia de clínica ampliada na atenção básica em saúde. Contextos Clínicos, 8(2), 141-152. http://dx.doi.org/10.4013/ctc.2015.82.03

Bauer, M. (2002). Análise de conteúdo clássica: uma revisão. In M. Bauer \& G. Gaskell (Orgs.), Pesquisa qualitativa com texto, imagem e som: um manual prático (P. Guareschi, Trad., pp. 189-217). Petrópolis, RJ: Vozes. (Trabalho original publicado em 2000)

Boris, G., Melo, A., \& Moreira, V. (2017). Influence of phenomenology and existentialism on Gestalt therapy. Estudos de Psicologia, 34(4), 476-486. http://dx.doi.org/10.1590/1982-02752017000400004

Castanõn, G. (2007). Psicologia Humanista: a história de um dilema epistemológico. Memorandum, 12, 105-124. http://www.fafich.ufmg.br/ memorandum/a12/castanon01.pdf

Castelo-Branco, P., \& Cirino, S. (2016). Reflexões sobre a consciência na fenomenologia e na abordagem centrada na pessoa. Gerais: Revista Interinstitucional de Psicologia, 9(2), 241-258. http://pepsic.bvsalud.org/pdf/gerais/ v9n2/v9n2a07.pdf

Castelo-Branco, P., Matos, G. N., Sampaio, A. G. S., \& Amaral, B. R. (2017). Formação do psicólogo humanista: revisão sistemática. Perspectivas em Psicologia, 21, 73-92. http://www.seer.ufu.br/index.php/perspectivasempsicologia/ article/view/38925/20598

Castelo-Branco, P., \& Silva, L. (2017). Psicologia humanista de Abraham Maslow: recepção e circulação no Brasil. Revista da Abordagem Gestáltica, 23(2), 189-199. http://pepsic.bvsalud.org/pdf/rag/v23n2/v23n2a07.pdf

Cellard, A. (2008). A análise documental. In J. Poupart et al. (Orgs.), A pesquisa qualitativa:enfoques epistemológicos e metodológicos (A. Cristina, Trad., pp. 295-316). Petrópolis, RJ: Vozes. (Trabalho original publicado em 1997)

Conselho Nacional de Educação. (2004, 18 de maio). Resolução no 8, de 7 de maio de 2004. Institui as Diretrizes Curriculares Nacionais para os Cursos de Graduação em Psicologia. Diário Oficial da União, 1, 16-17. http:// portal.mec.gov.br/cne/arquivos/pdf/rces08_04.pdf

Costa, J.,Costa, A. L. F., Lima, F. C., Pessanha, V.C., \&Yamamoto, O. H. (2012). A produção científica sobre a formação do psicólogo no Brasil. Psicologia em Pesquisa, 6(2), 130-138. http://dx.doi.org/10.5327/Z1982-12472012000200006 
Faizibaioff, D., \& Antúnez, A. (2015). O aspecto pessoal (vivido) em Minkowski como fundamento diagnóstico e metodológico da Psicopatologia Fenômeno-Estrutural. Boletim: Academia Paulista de Psicologia, 35(88), 39-58. http://pepsic.bvsalud.org/pdf/bapp/v35n88/v35n88a04.pdf

Feijoo, A., \& Mattar, C. (2014). A fenomenologia como método de investigação nas filosofias da existência e na psicologia. Psicologia: Teoria e Pesquisa, 30(4), 441-447. http://www.scielo.br/pdf/ptp/v30n4/v30n4a09.pdf

Feijoo, A., \& Mattar, C. (2016). Encontros e desencontros nas perspectivas existenciais em psicologia. Psicologia em Revista, 22(2), 256-272. http://periodicos.pucminas.br/index.php/psicologiaemrevista/article/ view/P.1678-9523.2016V22N2P258/10745

Feijoo, A., \& Protasio, M. (2015). Kierkegaard's ideas on clinical psychology and psychotherapy with children. International Journal of Psychotherapy, 26(1), 145-153. http://connection.ebscohost.com/c/articles/101825835/ kierkegaards-ideas-clinical-psychology-psychotherapy

Ferreira Neto, J. (2004). A formação do psicólogo: clínica social e mercado. São Paulo, SP: Escuta.

Ferreira Neto, J. (2017). Psicologia, políticas públicas e o SUS. São Paulo, SP: Escuta.

Forghieri, Y. (Org). (1984). Fenomenologia e psicologia. São Paulo, SP: Cortez.

Forghieri, Y. (1989). Contribuições da fenomenologia para o estudo das vivências. Revista Brasileira de Pesquisa em Psicologia, 2(1), 7-20.

Gomes, W. (1985). O eidético e o empírico na psicologia fenomenológica. Estudos de Psicologia, 2(2), 135-148.

Gomes, W., \& Castro, T. (2010). Clínica fenomenológica: do método de pesquisa para a prática psicoterapêutica. Psicologia: Teoria e Pesquisa, 26(spe), 81-93. http://dx.doi.org/10.1590/S0102-37722010000500007

Gomes, W., Holanda, A., \& Gauer, G. (2004). História das abordagens humanistas em psicologia no Brasil. In M. Massimi (Org.), História da psicologia no Brasil do Século XX (pp. 105-129). São Paulo, SP: EPU.

Goto, T. (2015). Introdução à psicologia fenomenológica: a nova psicologia de Edmund Husserl (2a ed.). São Paulo, SP: Paulus.

Grynzspan, M. (2012). Por uma sociologia histórica da recepção e da circulação de textos. Revista de Sociologia e Política, 20(44), 11-30. http://dx.doi.org/10.1590/S0104-44782012000400002

Holanda, A. (1997). Fenomenologia, psicoterapia e psicologia humanista. Estudos de Psicologia, 14(2), 33-46. http:// dx.doi.org/10.1590/S0103-166X2010000200013

Holanda, A. (2014). Fenomenologia e humanismo: Reflexões necessárias. Curitiba, PR: Juruá.

Krüger, H. (2014). Psicologia humanista. In S. Araújo, F. Caropeso, G. Castanõn, \& R. Simanke (Orgs.), Fundamentos filosóficos da psicologia contemporânea (pp. 165-198). Juiz de Fora, MG: EDUFJF.

Macedo, J.-P., Lima, M., Dantas, C., \& Dimenstein, M. (2017). Transnacionalização do ensino superior: Impactos nos processos formativos em psicologia no Brasil. Psicologia: Ciência e Profissão, 37(4), 852-868. http://dx.doi.org/10.1590/1982-3703004272016

Orengo, F. (2017). O que o psicólogo compreende por psicologia fenomenológica (Dissertação de mestrado). Universidade Federal do Paraná, Curitiba, PR.

Perls, F. (1988). A abordagem gestáltica e testemunha ocular da terapia (J. Sanz, Trad.). Rio de Janeiro, RJ: LTC. (Trabalho original publicado em 1973)

Ponte, C., \& Sousa, H. (2011). Reflexões críticas acerca da psicologia existencial de Rollo May. Revista da Abordagem Gestáltica, 17(1), 47-58. http://pepsic.bvsalud.org/pdf/rag/v17n1/v17nla08.pdf

Prestelo, E. (2012). A história da Gestalt-terapia no Brasil: "peles vermelhas" ou "caras-pálidas". In A. Jacó-Vilela, A. Crezzo., \& H. Rodrigues (Orgs.), Clio-Psyché hoje: Fazeres e dizeres Psi na história do Brasil (pp. 88-96). Rio de Janeiro, RJ: Relume-Dumará.

Rogers, C. (2009). Tornar-se pessoa (M. Ferreira \& A. Lamparelli, Trads.). São Paulo, SP: Martins Fontes. (Trabalho original publicado em 1961)

Scorsolini-Comin, F. (2015). Plantão psicológico e o cuidado na urgência: panorama de pesquisas e intervenções. Psico-USF, 20(1), 163-173. http://dx.doi.org/10.1590/1413-82712015200115

Yamamoto, O., \& Costa, A. (2010). Escritos sobre a profissão de psicólogo no Brasil. Natal, RN: EDUFRN. 
Gabriel Nery Matos

Graduado em Psicologia pela Universidade Federal da Bahia (UFBA), Salvador - BA. Brasil.

E-mail: gabrielnerymatos95@gmail.com

(D) https://orcid.org/0000-0001-9049-1015

\section{Paulo Coelho Castelo Branco}

Docente do Departamento de Psicologia da Universidade Federal do Ceará (UFC) e do Mestrado em Psicologia da Saúde da Universidade Federal da Bahia (UFBA). Doutor em Psicologia pela Universidade Federal de Minas Gerais (UFMG). Coordenador do Núcleo de Estudos em Psicologia Humanista, Fortaleza - CE. Brasil.

E-mail: pauloccbranco@gmail.com

(D) https://orcid.org/0000-0003-4071-3411

\section{Tommy Akira Goto}

Professor adjunto do Curso de Psicologia da Universidade Federal de Uberlândia (UFU). Doutor em Psicologia pela Pontifícia Universidade Católica de Campinas (PUC-Campinas). Presidente fundador da Associação Brasileira de Psicologia Fenomenológica (Abrapfe). Membro colaborador do Círculo Latinoamericano de Fenomenologia (Clafen), Uberlândia - MG. Brasil.

E-mail: prof-tommy@hotmail.com

(D) https://orcid.org/0000-0003-4972-7801

Endereço para envio de correspondência:

Universidade Federal do Ceará. Avenida da Universidade, 2762, Departamento de Psicologia/gabinete 5, Benfica. CEP: 60.020.180. Fortaleza - CE. Brasil.

Recebido 27/02/2018

Aceito 14/08/2018

Received 27/02/2018

Approved 14/08/2018

Recibido 27/02/2018

Aceptado 14/08/2018

Como citar: Matos, G. N., Castelo Branco, P. C., \& Goto, T. A. (2020). Perfil de Docentes Humanistas, Fenomenológicos e Existenciais: Análise de Editais de Concursos. Psicologia: Ciência e Profissão, 40,1 -13. https://doi.org/10.1590/1982-3703003192258

How to cite: Matos, G. N., Castelo Branco, P. C., \& Goto, T. A. (2020). Profile of Humanistic, Phenomenological and Existential Teachers: Analysis of Public Selection Publications. Psicologia: Ciência e Profissão, 40, 1-13. https://doi.org/10.1590/1982-3703003192258

Cómo citar: Matos, G. N., Castelo Branco, P. C., \& Goto, T. A. (2020). Perfil de Docentes Humanistas, Fenomenológicos y Existenciales: Análisis de Edítales de Concursos. Psicologia: Ciência e Profissão, 40, 1-13. https://doi.org/10.1590/1982-3703003192258 